\title{
QUE ESTÁ MUDANDO NA GESTÃO PÚBLICA BRASILEIRA? tendências sugeridas pelos programas inscritos
}

\author{
Marta Ferreira Santos Farah \\ Vice-Diretora do Programa GESTÃo PúBLICA E CIDADANIA \\ Fundação Getulio Vargas
}

O Ciclo de Premiação 1996 do Programa GESTÃo PÚBLICA E CIDADANIA teve um número expressivo de inscrições - 629 projetos, programas ou atividades de todo o país - sinalizando, de um lado, a existência de um movimento importante de busca de soluções para os graves problemas que atingem os cidadãos e, de outro, a necessidade de se criarem canais para divulgação das iniciativas em curso, em geral confinadas à própria localidade onde ocorrem e a uma rede informal de troca de experiências.

O banco de dados constituído a partir do material básico enviado pelos programas inscritos permite não apenas conhecer cada iniciativa singular mas também considerar o conjunto de programas inscritos em 1996, do ponto de vista de aspectos como distribuição regional, áreas de atuação governamental, nivel de governo, articulação intersetorial, parcerias com sociedade civil etc. O material reunido permite, também, ainda que preliminarmente, dado o caráter sumário das informações disponíveis para a maior parte dos programas, identificar algumas tendências de mudança na administração pública brasileira, em particular no nível municipal de governo.

O primeiro ponto a destacar diz respeito à alta participação de programas municipais: das 629 inscrições, 488 (78,5\%) foram feitas por órgãos municipais. Esta predominância da iniciativa local pode ser atribuída a um conjunto de fatores. Em primeiro lugar, o momento em que o GESTÃO PÚBLICA E CIDADANIA foi lançado, coincidindo com o último ano de governo na esfera municipal, facilitou a inscrição de programas com no mínimo um ano de efetivo funcionamento, condição estabelecida pelo próprio regulamento. Por outro lado, o interesse de divulgação de iniciativas governamentais tende a ser maior em ano eleitoral.

Mas o grande peso das iniciativas municipais no conjunto das inscrições pode ser também um reflexo da importância crescente das ações do governo local no país nos últimos anos, o que, por sua vez, pode ser atribuído, entre outros, aos seguintes fatores: 
1. transferência de atribuições do governo central para outros níveis de governo, em particular para o governo municipal, sobretudo daquelas que dizem mais diretamente respeito à cidadania social;

2. resposta a reivindicações da sociedade civil por descentralização das políticas sociais, desde o início da década de 80;

3. ênfase à descentralização na agenda de. reforma proposta por diferentes correntes políticas;

4. aumento significativo da participação dos municípios na repartição dos recursos fiscais desenhada a partir da Constituição de 1988;

5. ênfase à descentralização na agenda de organismos financiadores internacionais, os quais exercem influência - direta ou indireta - sobre o desenho das políticas governamentais no país;

6. maior proximidade do governo local com relação às demandas da população, o que assume importância num quadro democrático;

7. insuficiência das respostas do mercado como alternativa ao "desmonte" do Estado (e de suas políticas) no nível federal;

8. tendência de o governo municipal passar a se preocupar com o desenvolvimento da economia local, no quadro da globalização.

No que se refere à distribuição regional das inscrições, a maior concentração verificou-se na região Sudeste, de onde são $60,7 \%$ dos programas inscritos, seguindo-se a região Sul, com $21,3 \%$, e o Nordeste, com $9,9 \%$ do total das inscrições. Há programas também das regiões Centro-Oeste $(5,1 \%)$ e Norte $(2,7 \%)$, enquanto $0,3 \%$ deles são inter-regionais. À exceção dos estados de Tocantins, Sergipe e Rio Grande do Norte, todas as unidades da federação tiveram programas inscritos (sejam da esfera estadual, sejam da municipal, ou ainda programas de organizações indígenas). As participações numericamente mais expressivas foram as do Estado de São Paulo (184 programas, correspondendo a 29,3\% das inscrições); Minas Gerais (142 programas, 22,6\% das inscrições); Paraná (55 programas, $8,7 \%$ das inscrições) e Rio Grande do Sul (54 programas, 8,6\% das inscrições).

Há programas inscritos em diversas áreas de ação de governo. É importante observar que éstas áreas são as indicadas pelos responsáveis pela inscrição, correspondendo algumas a setores de ação de governo e outras a mecanismos ou formas de gestão. Considerou-se importante nesta compilação dos programas inscritos preservar as áreas indicadas originalmente. Análises posteriores, interessadas seja em determinado setor, seja no processo de gestão, deverão reclassificar os programas, uma vez que o critério de classificação variou de programa para programa. Assim, por exemplo, há um número maior 
de programas na área de habitação do que o indiçado a seguir, pois parte dos programas deste setor foi classificada na área "participação popular", considerada como o principal fator de inovação pelos responsáveis pelos programas.

As doze áreas em que ocorreu maior incidência de inscrições são destacadas na tabela abaixo:

Programas inscritos no Ciclo de Premiação 1996 do GESTÃO PÚBLICA E CIDADANIA segundo as áreas de atuação governamental

\begin{tabular}{l|r|r}
\hline \multirow{2}{*}{ áreas } & \multicolumn{2}{|c}{ programas inscritos } \\
\cline { 2 - 3 } total & n.a. & $(\%)$ \\
educação & 629 & 100,0 \\
saúde & 98 & 15,6 \\
criança e adolescente & 81 & 12,9 \\
cultura, lazer e esporte & 50 & 8,0 \\
formas de gestão e planejamento & 38 & 6,0 \\
habitação & 38 & 6,0 \\
participação popular & 29 & 4,6 \\
desenvolvimento regional e local & 29 & 4,6 \\
agropecuária e pesca & 21 & 3,3 \\
desenvolvimento sustentável & 20 & 3,2 \\
assistência social & 18 & 2,9 \\
geração de emprego e treinamento para o & 18 & 2,9 \\
trabalho & 16 & 2,5 \\
demais áreas & & 27,5 \\
\hline
\end{tabular}

A distribuição dos programas de âmbito municipal revela, por sua vez, que as iniciativas de mudança na gestão pública municipal não provêm. apenas de cidades de grande porte. Cidades médias e pequenos municípios também se inscreveram com programas em diversas áreas, o que, por um lado, chama a atenção para a problemática social, econômica e política dos pequenos e médios municípios e, por outro, mostra que a busca de soluções alternativas e de novas formas de gestão não é um monopólio dos grandes centros. A título de ilustração de programas inscritos por municípios de pequeno porte e que foram premiados entre as vinte melhores iniciativas, podem ser mencionados:

- Projeto Conviver (p.79), programa para idosos, da Prefeitura de Duque Bacelar, no Maranhão, município de 7.538 habitantes ${ }^{1}$;

- Fundo de Desenvolvimento Agropecuário (p.86), programa de apoio ao pequeno produtor rural, desenvolvido pela Prefeitura de Tupandi, no Rio Grande do Sul, município cuja população era de 2.325 habitantes $^{1}$. 
A análise preliminar do material recebido para inscrição dos programas permite, finalmente, que se identifiquem algumas tendências de inovação na gestão pública brasileira. É possível identificar dois eixos principais de inovação, considerando-se os 629 projetos inscritos ${ }^{2}$ :

1. o tipo e o conteúdo das políticas (novas políticas);

2. o processo político e a gestão de políticas públicas (novas formas de gestão, novos processos decisórios, novas formas de provisão de serviços).

\section{NOVAS POLÍTICAS}

No que se refere ao conteúdo das políticas, foi possível identificar os seguintes tipos de iniciativas inovadoras:

\section{a. Novas políticas em setores tradicionais}

A inovação se dá, neste caso, através de mudanças na concepção sobre a natureza dos serviços prestados, com repercussões sobre a própria política. Constituem exemplo deste tipo de inflexão ações na área da saúde, em que medidas de caráter preventivo substituem o padrão exclusivamente curativo que vinha prevalecendo neste setor ${ }^{3}$. Dentre os projetos ou programas inscritos há vários com esta perspectiva, como os programas de saúde da família, em que se enfatiza a "formação" para a saúde no próprio espaço familiar, em oposição aos programas tradicionais voltados ao tratamento da doença. Tal perspectiva tem como um de seus desdobramentos importantes a necessária superação da abordagem exclusivamente setorial, envolvendo a integração em projetos comuns de ações de saúde, educação, alimentação, habitação etc. Podem ser citados como exemplos desta perspectiva:

- $\quad$ Programa de Saúde da Família no Mutirão do Serrotão, de Campina Grande - PB (p.57);

- Saúde Global, de Joaíma - MG (p.57);

- $\quad$ Programa Médico de Família, de Londrina - PR (p.58);

- $\quad$ Programa Nutrir, de Apucarana - PR (p.57).

\section{b. Novas políticas para preocupações emergentes}

Algumas das iniciativas inscritas têm o caráter de novas respostas a novos desafios. Assim, por exemplo, na área de educação, ao lado de políticas voltadas à universalização da oferta, problema ainda existente em algumas regiões do país, surgem novas políticas, voltadas ao combate à evasão, à 
repetência e à melhoria da qualidade de ensino. Vários dos programas inscritos têm esta orientação, como, por exemplo:

- $\quad$ Projeto Desafio, de Ipatinga - MG (p.48);

- $\quad$ Programa Municipal de Transporte Escolar, de Itajá - GO (p.46).

\section{c. Novas políticas para novas clientelas}

Alguns dos projetos e programas inscritos destinam-se a segmentos da população tradicionalmente não atendidos, assinalando um movimento no sentido da ampliação do espaço da cidadania. Assim, há ações governamentais voltadas aos idosos, aos deficientes, à mulher, e aos moradores de rua, como nos exemplos que seguem:

- $\quad$ Programa Intersecretarial de Atendimento à Terceira Idade, de São Paulo - SP (p.79);

- Assistência Odontológica ao Deficiente Mental e Portador de Paralisia Cerebral, em Araçatuba - SP (p.82);

- Réde Nacional de Comunicação entre Portadores de Deficiência - RENDE, do Estado de São Paulo (p.82);

- $\quad$ Projeto Casa Rosa Mulher, de Rio Branco - AC (p.80).

- $\quad$ Centro de Atendimento à Mulher, de Londrina - PR (p.80);

- República Reviver, de Belo Horizonte - MG (p.84).

Este é o caso também dos diversos projetos e programas voltados a crianças e adolescentes ( $8,0 \%$ das inscrições). Trata-se de programas que buscam alternativas para a reinserção social de crianças e adolescentes em situação pessoal ou social de risco, baseados na noção de direito, caracterizando uma ruptura com relação às políticas tradicionais dirigidas ao "menor", podendo ser citados, a título de exemplo, os seguintes:

- $\quad$ Programa de Atendimento à Criança e Adolescente, de Canoinhas - SC (p.77);

- $\quad$ Programa Cidade Mãe, de Salvador - BA (p.74);

- $\quad$ Campanha Seja um Anjo da Guarda, de Santos - SP (p.78).

\section{d. Políticas locais de combate à pobreza e de desenvolvimento local}

Há projetos e programas em todo o país voltados à geração de emprego e renda e ao desenvolvimento local, os quais parecem assinalar uma inflexão importante no sentido da ampliação da 
esfera de ação do governo local: da prestação de serviços urbanos clássicos ou de políticas sociais tradicionais para a formulação e implementação de políticas geradoras de atividade econômica e de renda. Como exemplos, podem ser citados:

- $\quad$ Programa de Geração de Emprego e Renda, de Quixadá - CE (p.90);

- Pólo Agroflorestal, de Rio Branco - AC (p.91);

- $\quad$ Fundo de Geração de Emprego e Renda - FUNGER, de Teresina - PI (p.90).

\section{NOVAS FORMAS DE GESTÃO (NOVOS PROCESSOS)}

O segundo eixo importante de inovação diz respeito aos processos políticos e à gestão de políticas públicas. É possível identificar, a partir dos casos inscritos no GESTÃo PÚBLICA E CIDADANIA, tendências de mudança na administração pública brasileira, manifestas no nível dos governos subnacionais. Estas tendências talvez assinalem um movimento de ruptura de algumas das características centrais da gestão pública no país, tais como: centralização decisória e financeira na esfera federal, fragmentação institucional, atuação setorial, clientelismo, padrão verticalizado de tomada de decisões e de gestão, burocratização e padronização de procedimentos, exclusão da sociedade civil dos processos decisórios, impermeabilidade das políticas e das agências estatais ao cidadão e ao usuário, e ausência de controle social e de avaliação das políticas públicas.

Dentre as tendências de mudança no padrão da administração pública que os programas inscritos permitem identificar, algumas devem ser destacadas.

\section{a. Mudanças nas relações entre Estado e Sociedade Civil}

Uma das características que mais se destaca em boa parte dos projetos e programas inscritos neste primeiro Ciclo de Premiação do GESTÃO PÚBLICA E CIDADANIA é o envolvimento de outros atores - ao lado do próprio governo - na formulação e implementação das políticas públicas, inclusive na provisão e gestão de serviços públicos: $42 \%$ dos programas resultam de ações conjuntas do governo e de entidades da sociedade civil - comunidade organizada, organizações não-governamentais e setor privado empresarial. Embora sob direção de uma entidade governamental, vários projetos se estruturam como redes de entidades e instituições, mobilizadas e articuladas em torno de um problema de interesse público, cujo enfrentamento ultrapassa a capacidade de ação isolada do Estado - seja por limites financeiros, seja pelo maior grau de "imersão" no problema que uma ação coordenada permite. 
Constituem exemplos de programas que envolvem parceria com a sociedade civil:

- $\quad$ Coleta de Sementes Nativas do Cerrado e Matas, de Franca - SP (p.43), que envolve, além da própria Prefeitura, uma ONG ambientalista, grupos de escoteiros, escolas privadas de ensino superior, uma fundação ligada ao setor empresarial etc.;

- Comissão Permanente de Investigação e Fiscalização das Condições de Trabalho no Estado do Mato Grosso do Sul (p.35), programa que atua em carvoarias, usinas de açúcar e álcool, plantio e colheita de algodão, braquiária e erva-mate, sob a coordenação da Secretaria Estadual da Cidadania, Justiça e Trabalho, articulando diversos órgãos estaduais e federais, além de ONG;

- $\quad$ CEASA - Empresa Municipal Auto-Sustentada, de Campinas - SP (p.89), que viabilizou inclusive a oferta de serviços à população de baixa renda;

- CEPAE, os Centros de Pais e Amigos das EMEls, de Franca - SP (p.35), que possibilitou o melhor aproveitamento dos equipamentos por parte da comunidade reduzindo significativamente as depredações dos prédios nos finais de semana.

Muitos programas inscritos têm como um de seus elementos constitutivos ou mesmo como preocupação central a participação do cidadão (participação popular) na formulação, na implementação e no controle e avaliação das políticas públicas. Ainda que parte destes casos possa não envolver uma participação efetiva, mas apenas a inclusão formal dos cidadãos em espaços específicos e limitados de gestão ou execução, é importante registrar a emergência de uma preocupação com a necessidade de inserção de novos atores no âmbito das políticas públicas. Assim é que a participação do cidadão aparece em programas das mais diversas áreas, como é o caso dos seguintes exemplos:

- Municipalização e Participação Popular, de Diadema - SP (p.28), na área de saneamento;

- Gerenciamento Comunitário, de Cuiabá - MT (p.32), na área de uso e ocupação do solo urbano;

- $\quad$ Porto Alegre Mais - Cidade Constituinte, de Porto Alegre - RS (p.27), na área de gestão e planejamento;

- Orçamento Participativo, de Ipatinga - MG (p.33), na área de orçamento;

- $\quad$ Circo da Cidade, de Lages - SC (p.69), na área de cultura;

- $\quad$ Ouvidoria Pública Municipal, de Santos - SP (p.28), na área de controle e acompanhamento de políticas.

A informação ao cidadão constitui um aspecto privilegiado por alguns programas, assinalando outro eixo da alteração na relação entre Estado e cidadão no âmbito das políticas públicas. Constituem 
exemplos de projetos com esta ênfase:

- $\quad$ Serviço 156, de São José dos Campos - SP (p.31);

- $\quad$ Programa Municipal de Informação ao Consumidor, de Juiz de Fora - MG (p.82);

- $\quad$ Sistema de Acompanhamento Orçamentário, de Angra dos Reis - RJ (p.29).

Finalmente, é possível identificar um traço comum a vários projetos, o qual contribui para a mudança qualitativa na relação entre Estado e cidadão: a maior adequação dos projetos ao público-alvo, rompendo-se com a padronização de caráter nacional que tendia a prevalecer em boa parte das políticas públicas no país. A inserção dos programas na comunidade local, a participação dos cidadãos na formulação das políticas e a articulação de diversos atores na implementação das políticas (aspecto enfatizado mais adiante) contribuem para esta maior adequação das políticas às necessidades específicas de cada local e de cada "clientela". A própria noção de clientela se redefine, à medida que o cidadão passa a estar "dos dois lados" do processo, deixando de ser o mero receptor passivo de pacotes prontos. Um projeto exemplar desta perspectiva é o:

- $\quad$ Projeto Jaburu, em Nova Xavantina - MT (p.25), de iniciativa da Associação dos Xavante de Pimentel Barbosa.

\section{b. Mudanças nas relações entre esferas de governo}

Diversos dos programas inscritos $(27 \%)$ envolvem uma nova forma de relação entre esferas de governo, estabelecendo-se articulações coordenadas entre as ações de governos municipais, estaduais e federal. Constituem exemplos os seguintes programas:

- Um Novo Modelo de Gestão, de Rondônia (p.27), no qual a política agrícola passa a ser decidida em conjunto por municípios e Estado (envolvendo ainda a participação de ONG);

- Curso de Administração Municipal, em Araraquara - SP (p.36), que é ministrado pela UNESP em parceria com o CEPAM e prefeituras de várias cidades.

As iniciativas que envolvem colaboração entre municípios e entre governos estaduais são, no entanto, ainda muito incipientes, totalizando não mais que oito casos (1,3\% dos inscritos). Constituem exemplos da articulação intermunicipal e da articulação interestadual, respectivamente:

- $\quad$ Programa Base Zero (p.40), na região semi-árida da Paraíba;

- POEMA - Pobreza e Meio Ambiente na Amazônia (p.40), naquela região. 


\section{c. Integração de ações e políticas públicas}

É possível constatar em parte significativa dos programas e projetos inscritos a emergência de uma nova forma de atuação governamental em que se tende a superar a setorialização das políticas públicas, através de ações integradas. Assim, alguns programas integram ações (e instituições) na área de saneamento e meio ambiente à geração de emprego e renda e à valorização do funcionário público, como é o caso do projeto:

- Modelo de Gestão de Resíduos Sólidos, de Belo Horizonte - MG (p.25).

Outros integram em programas de inserção social de crianças e adolescentes e de combate à pobreza, ações nas áreas de educação, saúde, cultura, entre outras, como por exemplo:

- $\quad$ Projeto Meninas de Santos, de Santos - SP (p.78);

- $\quad$ Programa Cidadão-Criança, de Vitória - ES (p.71);

- $\quad$ Programa de Garantia de Renda Mínima, de Campinas - SP (p.72);

- $\quad$ Programa Bolsa Familiar para a Educação / Bolsa-Escola, do Distrito Federal (p.46).

Há ainda programas habitacionais que envolvem ações na área de meio ambiente e de geração de emprego e renda, como os indicados abaixo:

- Ecomoradia, de Cuiabá - MT (p.63);

- Microurbanização Integrada do Castelinho, de Fortaleza - CE (p.63);

- $\quad$ Projeto São Pedro - Desenvolvimento Urbano Integrado e Preservação do Manguezal, de Vitória - ES (p.39).

\section{d. Mudanças na forma de gestão de organizações estatais}

Finalmente, constata-se a existência de um outro tipo de iniciativa por parte da administração pública, voltada à reforma da gestão interna da máquina estatal. Assim, há programas e projetos inscritos voltados à agilização de procedimentos, melhoria da qualidade de processos e a uma maior eficiência da ação estatal. Como exemplos, podem ser citados os projetos:

- SISDADANIA - Sistema Integrado de Cidadania, da Ouvidoria Geral do Paraná (p.33);

- Polícia Interativa, da Polícia Militar do Espírito Santo, em Guaçuí - ES (p.71);

- $\quad$ Postos de Serviço de Atendimento ao Cidadão, do Estado da Bahia (p.25);

- Jurisagilizar, do Tribunal de Justiça do Rio Grande do Sul (p.92).

- $\quad$ Administração Estratégica, de Vitória - ES (p.25). 
As iniciativas de governo apresentadas neste volume, em sua grande maioria, podem ser entendidas como parte de um processo incremental de mudança, que caminha no sentido da superação de diversas das características do padrão de gestão pública até recentemente prevalecentes no país. Uma primeira aproximação do material enviado pelos programas inscritos sugere uma forte ênfase na democratização dos processos, por um lado, e, ao mesmo tempo, a busca de uma maior eficiência e efetividade na ação estatal. É possível identificar um duplo movimento em direção à instauração e ampliação dos espaços de exercício da cidadania: de um lado, através da inclusão de novas políticas na pauta de ação do governo local, de outro, através da mudança na forma de decidir e implementar as políticas, configurando novos processos políticos e novas formas de gestão, em que se destaca, como elemento central, a ampliação do elenco de atores envolvidos na gestão pública, redefinindo a relação entre Estado e sociedade civil na esfera subnacional em nosso país.

\section{NOTAS}

1 FUNDAÇÃO INSTITUTO BRASILEIRO DE GEOGRAFIA E ESTATÍSTICA - IBGE. Censo Demográfico de 1991. Rio de Janeiro: IBGE, 1991.

2 É importante observar que não se procedeu aqui a uma análise mais aprofundada dos programas inscritos, no sentido de avaliar se de fato podem ser considerados inovadores. Considerou-se a sua inscrição no Gestão Pública e Cidadania como indicativa: 1. de uma ação da administração pública subnacional em determinada área; 2. de uma avaliação por parte da entidade responsável pelo programa de que este envolve alguma mudança com relação à ação estatal anterior (na área ou no local).

Evidentemente, a perspectiva que privilegia a abordagem preventiva não é nova, havendo certamente casos anteriores de programas com este caráter. Mas, como já mencionado, considerou-se inovação, no âmbito do Programa GESTÃO PÚBLICA E CIDADANIA, mudanças, ainda que simples, pequenas e de caráter incremental, que viabilizem transformações em práticas anteriormente predominantes, o que certamente é o caso do exemplo mencionado. 